\title{
As AÇõES FísICAS E O PROBLEMA CORPO-MENTE
}

\author{
Sandra Meyer ${ }^{1}$
}

\section{Introdução}

Uma das grandes revoluções do teatro do século XX foi desencadeada pelo viés pedagógico do diretor e encenador russo Constantin Sergueevich Stanislavski (1863-1938). Trata-se do reconhecimento de que o ofício do ator não visa somente o entretenimento, mas é uma forma de conhecimento. As investigações de Stanislavski permanecem como referência para os estudos teatrais e, especialmente, para a formação do ator, no Brasil e no mundo. Sua metodologia, constantemente auto-avaliada, continua como um sistema aberto e vivo, capaz de gerar questões fundamentais para a investigação do trabalho do ator, na atualidade.

Stanislavski teria formulado os principais problemas ontológicos e metodológicos da atividade do ator, tendo investigado a natureza e a ciência de seus processos "mental-fisico-emocionais", como lembra o diretor inglês Peter Brook (Apud GROTOWSKI, 1992: 9). Stanislavski apontou para a necessidade do "trabalho do ator sobre si mesmo", propondo novos entendimentos acerca de como o ator conhece e elabora seus processos cognitivos, com questões referentes às relações entre corpo e alma, ou corpo e mente, enunciadas por eles como aspectos físicos e psíquicos.

Neste artigo, proponho um entendimento de que, através do método das ações físicas, Stanislavski enunciou uma determinada relação entre cognição e ação, a que denomino como uma cognição na ação, e que conformaria uma teoria do corpo para o ator. A natureza dos processos mentais e suas relações com mundo físico - nomeada como o "problema corpo-mente", é uma das questões ontológicas mais insistentes e debatidas e, até pouco tempo, era alvo

IProfessora de Dança e Técnicas Corporais do Curso de Licenciatura em Teatro do Centro de Artes da Universidade do Estado de Santa Catarina - UDESC. Doutora em Comunicação e Semiótica Artes, pela Pontifícia Universidade Católica de São Paulo

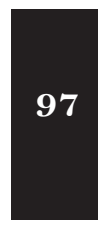


de indagação da filosofia, principalmente. Contudo, nos últimos 30 anos, tem sido cada vez mais central para as novas ciências da mente (CHURCHLAND, 2004). Nos últimos trinta anos a área cognitiva desenvolveu-se enormemente, através da convergência de especialidades tais como a química, a neurobiologia, a filosofia, a matemática, a biologia molecular, a física e a inteligência artificial, entre outras, delimitando uma recente área do conhecimento: as ciências cognitivas. Algumas questões referentes à pesquisa das ações físicas do ator formuladas por Stanislavski permitem estabelecer diálogos com teorias contemporâneas do conhecimento, especialmente no que se refere às relações entre corpo e mente.

A busca de integração das dimensões "interior e exterior" ou "física e espiritual" do ator foi constante na trajetória artística de Stanislavski e configurou procedimentos de ignição dos aspectos mentais e corporais, numa unidade psicofísica que justificaram a sua ação. O diretor e pedagogo argentino Raúl Serrano (2004), em sua obra Nuevas tesis sobre Stanislavski salienta que os textos escritos por volta de 1934 e os quatro anos que se seguem até sua morte reúnem um material inquestionável para a formulação de uma pedagogia teatral de caráter mais científico, no sentido de sua sistematização. É quando Stanislavski formaliza o método das ações físicas, um marco epistemológico indiscutível para as teorias do ator contemporâneo. A noção de ação física teve um papel central na nova configuração pedagógica, ressaltada como chave para que a criação e a emoção surgissem, já que não poderiam ser despertadas inteiramente pela vontade ou consciência do ator. Neste sentido, a estratégia de conhecimento foi alterada, pois é a partir das ações do corpo que o ator articularia os demais elementos da representação e se aproximaria da "natureza criadora".

Stanislavski estabeleceu, no início do século XX, procedimentos que apontavam para novos entendimentos acerca dos processos de conhecimento e aprendizagem nas relações entre corpo e mente, e que foram desenvolvidos por Jerzy Grotowski (1933-1999) na segunda metade do mesmo século. Este direcionamento implicava num conhecimento operativo e numa experiência de transformação, eminentemente prática, das conexões entre os estados físicos e os não físicos, enunciados pelos encenadores como estados espirituais. $\mathrm{Na}$ escuta do corpo, outras conexões se estabeleceram.

\section{O método das ações físicas - a práxis proposta por Stanislavski}

Eis como abordo um novo papel. Sem realizar a leitura prévia, sem qualquer conferência sobre a peça, os atores são convocados para ensaiá-la. (STANISLAVSKI, 1995: 225). 
Em meio à reação perplexa frente a sua proposição, o diretor Tórtsov, porta-voz fictício de Constantin Stanislavski para suas narrativas, insiste para que os atores executem pequenos objetivos físicos por meio de ações, pesquisando sua lógica e consecutividade com sinceridade e verdade mesmo sem terem analisado detalhadamente a personagem, como comumente faziam. Esta proposta contrapunha-se aos métodos de atuação já estabelecidos por tradições teatrais anteriores e pelo próprio Stanislavski, e representa uma mudança de entendimento das estratégias possíveis de conhecimento do ator no início do século XX.

Como salienta Serrano (2004), as teorias de atuação de Stanislavski formam um sistema que pode ser analisado a partir dos aspectos nomeados por ele como físicos e psíquicos. A preparação do ator ${ }^{2}$ aborda os aspectos mais subjetivos do processo do ator, incluindo as investigações sobre a memória e o subconsciente. A construção da personagem ${ }^{3}$ define alguns procedimentos, onde a questão do corpo já ganha maior status, como a caracterização física, a forma de tornar expressivo o corpo, o tempo-ritmo e plasticidade no movimento, a dicção e o canto, títulos estes que abrem os capítulos do livro. A expressividade da interpretação do ator dependeria também do grau de preparação física, uma vez que a técnica ajudaria na construção do papel. Em A Criação de um papel os aspectos ditos subjetivos e objetivos, físicos e psíquicos são mais claramente enunciados por Stanislavski como indissociados. Esta busca de unidade entre corpo e espírito é estabelecida por meio dos estados conscientes e inconscientes, e é a ação física a estratégia para a ignição do trabalho do ator.

Stanislavski aborda, acima de tudo, a complexidade do organismo humano e seu sistema de atuação não pode ser compreendido, plenamente, sem as conexões com as teorias psicofísicas de sua época. Enfatizo que não é uma relação de causa e efeito, ou de influência de procedimentos da ciência na arte, mas do compartilhamento de processos de conhecimento e hipóteses investigativas num determinado contexto. $\mathrm{O}$ diretor russo elaborou questões ontológicas, filosóficas e epistemológicas sobre o trabalho do ator a partir de procedimentos extremamente experienciais, e constantemente autoavaliados, provenientes da própria arte teatral, e que não se restringiam a uma abordagem teórica, no sentido do estabelecimento de categorias gerais ou a priori. "Arte não é ciência”, reconhece Stanislavski (1995:80), embora, para ele, o artista devesse buscar, constantemente, materiais e conhecimentos na vida e na ciência.
${ }^{2} \mathrm{~A}$ Preparação do Ator foi publicado em Nova York em 1936, traduzido por Elizabeth Reynolds Hapgood a partir de um manuscrito enviado pelo autor. Em 1964, foi publicado no Brasil a partir da versão americana. Já a tradução em espanhol utilizada neste trabalho - El trabajo del actor sobre si mesmo. El trabajo del actor sobre si mismo en el proceso creador de las vivencias (Buenos Aires: Domingo Cortizo - Editorial Quetzal S.A., 1986)

- foi realizada por Salomón Merener da edição russa do Editorial Estatal Arte, do Instituto Estatal de Investigações Científicas de Teatro e Música Maximo Gorki, de Moscou.

${ }^{3}$ Título proveniente da tradução inglesa Building a character traduzido por Pontes de Paula Lima, em 1970. A Construção da Personagem só seria publicado em língua inglesa em 1949, 13 anos após A Preparação do Ator. Título da tradução em espanhol utilizada neste trabalho - $E l$ trabajo del actor sobre si mesmo. El trabajo sobre si

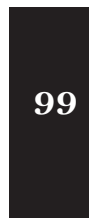




\section{Urdimento}

${ }^{5}$ Em Minha vida na arte, Stanislavski (1989) define seu método como dividido em duas partes: 0 trabalho do ator sobre si mesmo e sobre o papel, utilizados como títulos em suas obras publicadas na Rússia. 0 trabalho sobre si mesmo implicaria num processo de conhecimento e treinamento do corpo, da voz, da memória, da concentração, do relaxamento, e o trabalho sobre o papel ocorreria após 0 ator adquirir os meios técnicos necessários para realizar suas intenções.
É certo que utilizamos também termos científicos, como por exemplo, "subconsciente", "intuição", mas não no seu sentido filosófico, senão no mais simples, o da vida cotidiana. Não é culpa nossa que o domínio da criação cênica tem sido menosprezado pela ciência, que não tenha sido investigado e que não contemos com as palavras necessárias para a atividade prática. Tivemos que partir de nossos próprios meios, um pouco caseiros (STANISLAVSKI, 1986: 42).

A investigação junto a seus atores apresenta uma consistente contribuição para os estudos do corpo e da ação, por meio de questões sobre a relação corpo e mente e corpo e ambiente. As questões que Stanislavski (1989) propôs possibilitam ao ator "trabalhar sobre si mesmo e sobre a personagem", apontando para procedimentos a respeito de como o ator conhece e se conecta com o seu ambiente, se relaciona com sua memória, imaginação, consciência, inconsciente e vontade, e altera seus estados corporais e mentais. O sistema de Stanislavski enfatizou a dimensão prática do trabalho do ator por meio do problema mente-corpo, sendo as reflexões quanto ao método das ações físicas o ápice desta dimensão.

Em outras palavras, não analisamos nossas ações com a razão, friamente, teoricamente, mas as atacamos pela prática, do ponto de vista da vida, da experiência humana [...] trata-se de um processo de análise interior e exterior de nós mesmos, como seres humanos nas circunstâncias da vida de nosso papel. (STANISLAVSKI, 1995: 249).

O método das ações físicas é enunciado por Stanislavski como o resultado das investigações de toda a sua vida, após um período inicial de pesquisas relacionadas aos processos emocionais. Porque ele utilizou o termo ação "física" ao invés de "psicofísica"? Esta questão apontada por Richards (2001) importa na medida em que a busca de Stanislavski é permeada, todo o tempo, pela união entre corpo e espírito, nas dimensões físicas e psíquicas do ator. $\mathrm{O}$ termo ação física, no entanto, não pode ser entendido como exclusão ao que é comumente descrito como não físico, mas a partir da premissa de que a entidade física carrega a dimensão psíquica ou espiritual, sendo possível ser vislumbrada do exterior, ou seja, na visibilidade da ação do corpo. A ação física não deve ser reduzida a uma atividade física, mas expressar toda a complexidade da lógica da conduta que corresponde a uma dada situação. Stanislavski interroga: 
De que se ocupa Lady Macbeth no momento culminante da tragédia? De um ato físico simples: limpar com a mão a mancha de sangue [...], na vida real, muitos dos grandes momentos de emoção se manifestam em movimentos corriqueiros, pequenos e naturais (STANISLAVKI, 1986:192).

O pequeno ato, no caso de lavar as mãos, adquire sentido na medida em que se alternam, por exemplo, a preocupação com o vestígio da mancha de sangue, a perturbação do momento e a memória de momentos do assassinato ocorrido. Na lógica das ações físicas o ator deve justificar seus atos, ou seja, explicitar fisicamente as razões internas que o levaram a tal situação. O mais importante não é o que é dito, mas o que está na conduta acional e o ator deve ter clareza da razão (ou emoção) que levou o personagem a agir de certo modo, se movido pelo altruísmo, inveja, ódio.

Ao requisitar o comprometimento do corpo do ator na experiência, Stanislavski não excluiu a necessidade do pensar ou do analisar, mas instaurou uma espécie de deslocamento da atividade cognitiva. Ao invés da exclusiva análise por meio das operações eminentemente cerebrais (o "frio" cérebro) ou mentais, ele propôs ao ator pensar com suas ações, ou seja, pensar com todo o seu corpo. Esta formulação permite estabelecer conexões com as mais recentes abordagens das ciências cognitivas. O conhecimento do que o corpo em ação experimenta e desencadeia favorece a construção de outro tipo de entendimento para os processos cognitivos, secularmente creditados a incidência e hegemonia de uma mente (enquanto uma entidade imaterial) sobre um corpo que se faz instrumento.

\section{Organicidade na ação}

Quando formula o método das ações físicas o mestre russo admite que o corpo em ação fornece um caminho mais natural e seguro para que o ator atinja uma postura cênica. Não é sem motivo que a palavra drama é derivada de ação ${ }^{6}$, e o ator, visto como aquele que age, posto que "a vida é ação", enfatiza Stanislavski (1995: 63). Esta descoberta estava relacionada à constatação de que não há controle sobre os sentimentos, sob o entendimento de que os fenômenos do espírito são imateriais e evanescentes. Esta é, segundo Grotowski (1990), a grande revelação do último período de investigação daquele que ele considerava como seu mestre. Isolados das suas causas naturais, as emoções e sentimentos deveriam ser revividos através de um processo introspectivo e a mente e a vontade seriam as responsáveis por desencadeá-los. As emoções
${ }^{6} \mathrm{O}$ drama pode ser definido etimologicamente como em ação, do original grego

Spãua. Stanislavski salienta que no sentido grego, a ação refere-se à literatura,

à dramaturgia, à poesia, e não ao ator e sua arte. Ainda assim, 0 ator tem direito de apropriarse do termo.

(STANISLAVSKI, 1995:62).

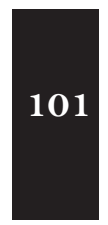


do ator estavam, para o diretor, ligadas à evocação de resíduos da memória de suas experiências, passíveis de serem relacionadas às da personagem e em circunstâncias dadas. Estas circunstâncias diziam respeito aos elementos, geralmente ditados pelo texto teatral, referentes ao contexto existencial e histórico da personagem e aos demais aspectos da encenação.

Com o método das ações físicas, o universo afetivo guardado na memória do ator e, anteriormente, despertado por meio de processos mentais, passa a ser atualizado pelo corpo. O ator é motivado a responder a questão do "reviver" experiências "organicamente", através da improvisação de ações físicas. Stanislavski procurava influir de modo indireto sobre as vivências mediante a lógica e coerência das ações. Ainda assim, adverte Isaacsson (2004), não significa que Stanislavski tenha afirmado, categoricamente, que a ação gera a emoção, mas que os afetos podem ser estimulados pelo corpo. Não por um movimento qualquer, mas pela compreensão das razões e impulsos que motivam as ações. Por outro lado, Stanislavski afirma que a ação física é a chave para as emoções e a esfera criativa do ator, na medida em que percebe que os aspectos físicos e espirituais possuem elos indissociados. Vinculada ao corpo, a noção de memória das emoções é estendida, posteriormente, para a memória das sensações, fruto da experiência dos sentidos.

Não se pode interpretar somente a psicologia do personagem, ou a mera lógica e consequência do sentimento. Por meio deles, então, seguimos a linha mais firme e acessivel das ações físicas, observando nelas a mais estrita lógica e conseqüência. Uma vez que esta linha está inseparavelmente relacionada com a linha interior do sentimento, conseguimos, através das ações fïsicas, provocar a emoção. A linha da ação física se introduz lógica e consequentemente na partitura da personagem. Provavelmente agora, através de suas próprias sensações, conhecestes a relação existente entre as ações físicas e a causa interior dos impulsos, as tendências que os determinou. Este é o caminho que vai do exterior ao interior. Afirmada esta relação, repita muitas vezes a linha da vida física do corpo humano. Não só consolidareis as ações físicas nelas mesmas, mas também os impulsos interiores, e alguns deles podem, com o tempo, tornarem-se conscientes (STANISLAVSKI, 1988: 347-348).

A afirmação da opção metodológica via ações não parece ter sido de fácil aceitação inicial, em sua época. A idéia de que "uma série simples de ações físicas, realísticas, tem a capacidade de engendrar e criar a vida mais elevada de um espírito humano em um papel” causava estranhamento até entre os seus 
atores, já que o próprio diretor, anteriormente, orientava-os a penetrar nas vias do sentimento através da memória afetiva (STANISLAVSKI, 1995: 250). É conhecida a consonância inicial de Stanislavski com as teorias do psicólogo francês Théodule Ribot (1839-1916). Ele acessa as obras de Ribot traduzidas em russo e encontra uma ressonância científica para suas intuições acerca das experiências emotivas ${ }^{7}$. O fundador da psicologia científica francesa chamou a atenção para os fenômenos psicológicos inconscientes, questionou o estudo da memória como uma faculdade exclusiva da alma e elaborou uma definição biológica para esta.

A análise das ações físicas era realizada nas circunstâncias determinadas da personagem e pressupunha não a participação exclusiva do cérebro, mas o comprometimento de todo o organismo, via ação: "Vocês estarão em movimento e não parados num só lugar, ou pensando nas coisas com o seu intelecto. Vocês estarão em ação", argumenta o mestre russo ao salientar a importância de criar a vida física do papel (STANISLAVSKI, 1995: 245). O conhecimento adquirido pelos atores nos primeiros anos de investigação, através da análise via intelecto e emoção, e realizados nos exaustivos trabalhos de leitura de mesa parecia afastá-los, de alguma forma, da possibilidade de um conhecimento "encarnado", só possível através do corpo em ação. O que não quer dizer que Stanislavski teria negado totalmente a etapa do trabalho de mesa, ao propor o método das ações físicas. O que houve foi um desmanche dos limites e da seqüência entre estes dois processos, o de, primeiramente, "sentir e analisar o papel" e a posterior "corporificação" da lógica e consecutividade do personagem na ação .

Para o diretor russo, a mais simples ação física obrigaria o ator a criar "toda sorte de ficções imaginarias, circunstâncias propostas e 'ses”, demonstrando que a nova abordagem metodológica absorvia as suas descobertas anteriores (STANISLAVSKI, 1995: 250). O "como se" faria o ator se aproximar do universo da personagem, perguntando-se o que e como faria se estivesse nas circunstâncias deste. $\mathrm{O}$ acesso físico ao papel agiria como uma espécie de "isca" para fisgar o sentimento criativo, este mais difícil de manejar, mais "esquivo, efêmero e caprichoso" (STANISLAVSKI, 1995:162). A iniciação física dos papéis atenderia às ordens, aos hábitos e à disciplina. Sendo mais "material", o corpo é "convocável", admite o mestre russo, ao contrário dos processos mentais e do sentimento, que para ele pertenciam a uma esfera mais imaterial. Se as ações elaboradas pelo corpo fossem vividas sinceramente, com sentimento de fé e verdade, a "vida espiritual" do papel emergiria (STANISLAVSKI, 1995:169).
${ }^{7}$ Obras traduzidas em russo que foram, de acordo com Bogdam (1999), consultadas por Stanislavski: Les maladies de la memoire (1881), Les maladies de la voIonté (1883), La psycologie de l'attention (1889), la psychologie des sentiments (1896) e L'essai sur l'imagination (1900).

8"Não estou contra as discussões em si, nem tampouco contra o trabalho de mesa, mas contra realizá-Io no tempo indevido. Tudo tem que ter um tempo".

(STANISLAVSKI apud JIMENEZ, 1990: 242).

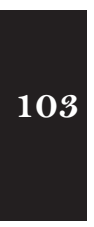




\section{Urdimento}

${ }^{9} \mathrm{O}$ desenvolvimento da ciência psicológica soviética assumiu um caminho diferente. Os cientistas soviéticos buscaram soluções para os principais problemas teóricos da psicologia com base no Marxismo. A partir de realizações de psicólogos estrangeiros foram elaboradas novas abordagens que permitiram elevar a psicologia soviética para um nível científico, contudo, com conceitos que se revelavam materialistas, preenchendo uma função ideológica.
$\mathrm{Na}$ concepção de Stanislavski, as ações são elementos do comportamento, ações elementares verdadeiramente físicas, mas ligadas ao fato de acionar outras ações. Neste sentido, os exercícios com objetos imaginários tiveram um papel pedagógico extraordinário. Através destes os alunos poderiam perceber a lógica e coerência das ações mais simples às mais complexas. Estes exercícios exigiam dos atores uma atenção aguçada, um trabalho intenso sobre a imaginação, controle da consciência, sentido de verdade e lembrança de sensações percebidas anteriormente. Desta forma, o ator evitaria as ações mecânicas não somente com a mente, mas com a sensação da sua própria natureza orgânica, física (STANISLAVSKI, 1986: 212).

\section{A dimensão cognoscível da ação física}

Muitos fatores determinaram o direcionamento de Stanislavski para uma pedagogia do corpo. Serrano (1996) aponta para as prováveis implicações políticas, pois a afirmação da materialidade do corpo estava próxima da formulação marxista, que sustentava a necessidade de começar o trabalho a partir das questões materiais e visíveis, para, só então, criar as condições para a aparição da vida espiritual. Para o mestre russo, o trabalho do ator no método das ações físicas partiria do corpo em direção a dimensão subconsciente. Ao abordar a atividade do ator de forma objetiva, Stanislavski dissipa o mito de que o processo criador é incognoscível (KRISTI apudSTANISLAVSKI, 1986). Anterior à abordagem objetiva, o enfoque idealista da psicologia estudava os fenômenos psíquicos separados de sua fisiologia, restringindo a leitura da atuação do ator a conceitos como talento, inspiração e genialidade, bem como não considerava suficientemente as condições histórico-sociais do ambiente. A partir da prática junto a seus atores, Stanislavski aproximou-se das posições da ciência materialista para investigar as leis objetivas do processo criador e estudar os elementos do sentimento por meio de uma abordagem psicofísica. A noção dualista que separava o sentimento interior (psíquico) e o aspecto exterior (físico) foi se dissipando frente à convicção da interdependência da natureza física e espiritual do processo criador.

Importa salientar o ambiente no qual ele estava inserido, dado que a União Soviética, neste período, tinha o marxismo como filosofia oficial. O método das ações físicas pode, de certa forma, ter respondido a estas demandas materialistas, associado aos estudos do fisiologista russo IvanPetrovitch Pavlov (1849-1936), cuja concepção biológica do comportamento teria fornecido argumentos para a leitura russa do materialismo dialético?

A convicção de que os elementos espirituais e físicos dos processos de criação estavam irremediavelmente ligados norteou as reflexões sobre a prática artística de Stanislavski. Por outro lado, Pidoux (1986:114) chega a afirmar que 
a concepção stanislavskiana de que o gesto pode suscitar o sentimento é baseada numa ontologia científica - numa espécie de "determinismo behaviorista" - e menos sobre uma reflexão estética, e esta seria menos flexível, processual e sutil que a de seus alunos (Meyerhold e Vakhtangov), que estariam mais avançados nesta pesquisa ${ }^{10}$. O "behaviorismo filosófico" aborda as emoções e as sensações não como episódios espirituais interiores, mas como um modo abreviado de falar sobre padrões de comportamento, potenciais ou reais (CHURCHLAND, 2004: 49).

Em detrimento de possíveis implicações behavioristas (que incorreriam em um comportamento mais determinista) e de possíveis pressões políticas provenientes do materialismo soviético, uma leitura contemporânea acerca das relações entre os fenômenos físicos e psíquicos hoje, por meio das ciências cognitivas, revela que as hipóteses de Stanislavski eram legítimas. Ele não negou a introspecção, o que foi alterada foi a estratégia de acesso a ela, o que pode ser constatado no método das ações físicas.

Na ação de um corpo no mundo há um processo complexo que envolve vários níveis do aparato cognitivo e Stanislavski intuiu que o conhecimento do ator envolveria um ponto de vista da experiência. O que o ator conhece não se resume a conceitos e idéias separadas de uma prática, pois é o corpo como um todo que aprende enquanto age. $\mathrm{O}$ entendimento do conceito de ação e, mais do que isso, a sua "encarnação" corpo é apontado como um dos desafios mais instigantes na prática do ator. Os momentos de desamparo e dúvidas na geração de ações justas e orgânicas para as personagens sempre ocorrerão, já advertia Stanislavski (1995), não importa quantos papéis o ator já tenha construído.

Considerando que é a ação do ator que conecta os elementos da atuação e a sua constituição é um processo de conhecimento, o tipo de práxis a que o ator está sujeito pede por uma estratégia de conhecimento onde o pensamento se dá no processo acional, ou seja, como salienta Grotowski (1992), num pensar em ação. A idéia de um pensar em movimento difere do entendimento cartesiano, onde a mente pensa e o corpo executa. Pensar e mover não são acontecimentos separados, mas aspectos de um mesmo processo cognitivo dinâmico, possibilitando ao ator situações cênicas constantemente reconstruídas. A mente discursiva, para Stanislavski e Grotowski, classificaria demasiado e prenderia o fluxo das ações no mundo. Desta forma, o conceito de pensamento passa a ser entendido enquanto uma ação experienciada no mundo e não somente processo que requisita uma mente ou razão separada, a "razão pura ou nobre" enfatizada historicamente pela filosofia ocidental.
${ }^{10} 0$ "parentesco" entre o método das ações físicas e a biomecânica concebida por Meyerhold se fortaleceu a partir do compartilhamento das idéias provenientes das teorias dos reflexos condicionados.

${ }^{11} 0$ sentido de encarnação empregado não se refere a algo imaterial que adentra o corpo, mas a corporificação, ou no termo inglês embodied das idéias, no sentido de algo que se torna conhecimento no corpo a partir da ação deste no mundo envolvendo o sistema sensório-motor.

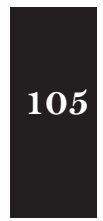




\section{Urdimento}

${ }^{12}$ Ver em Damásio (1996, 2000 e 2004), Dennett (1997) e Churchuland (2004).
Hoje, quase todas as teorias cognitivas que pesquisam estas questões não duvidam das implicações sensório-motoras e da fisiologia dos estados mentais e da correlação dos processos do corpo e da mente ${ }^{12}$. Ainda assim é possível detectar discursos e práticas artísticas que tratam o corpo como um instrumento de uma entidade imaterial e desencarnada (mente, alma ou espírito) e o pensamento separado do corpo. A extrema oposição entre matéria e mente, há algum tempo, foi abandonada pelas ciências da mente e um novo entendimento da relação corpo e mente requer o abandono da decantada idéia cartesiana de distinção abissal entre a mente e o corpo, da nítida divisão entre percepção, cognição e ação e da separação entre pensamento e ação.

Já detectada por encenadores como Eugenio Barba, a metáfora mecanicista não deveria se sustentar mais: “[ $[.$.$] o corpo não é um instrumento,$ não é algo que alguém possa forçar a se expressar" (BARBA, 1989: 32). O corpo não pode ser plenamente manipulado ou controlado por um comando central mental a priori, posto ser um "ente-em-vida", em constante estado de instabilidade e auto-organização, segundo uma complexa rede de conexões distribuídas por todo o organismo. O ator não tem um corpo. Ele é o seu corpo, e para entendê-lo, há que contemplá-lo em ação, em vida.

Stanislavski afirmou a natureza extensa e material do corpo, posto que é, incomparavelmente, mais "sólido" e pode ser "convocado", opondo-o a natureza intangível de estados internos como os sentimentos. Não obstante a esta atribuição dualista, sua busca pela unidade corpo-alma, quando concebeu o método das ações físicas, atribuiu ao corpo em ação uma possibilidade de desencadeamento de processos antes creditados, exclusivamente, aos processos mentais. Serrano (1996) enfatiza que a concepção cartesiana de corpo foi sendo modificada na medida em que o diretor russo avançava no método das ações físicas.

As observações de Stanislavski apontavam para o fato de que o ser físico do papel já criava a entidade espiritual, por sua conta e independente da vontade e consciência. Quanto mais os atos físicos eram realizados, mais definida ia se tornando a linha espiritual. Afirma Stanislavski (1995: 239) que, "em toda ação física, a não ser quando é puramente mecânica, acha-se oculta alguma ação interior, alguns sentimentos". Assim se formariam os dois planos da vida de um papel - o interior e o exterior. As idéias de Stanislavski aparentam, a princípio, uma dualidade nas relações entre corpo e espírito, interior e exterior, mas um olhar mais acurado revela a sua incansável investigação das conexões entre os fenômenos materiais e imateriais da conduta humana. A conclusão a que ele chega é que, apesar de serem substâncias distintas, há um elo entre o corpo e alma que é indissolúvel. E que os aspectos materiais e extensos do corpo também dão ignição e legitimam os processos criativos próprios à entidade espiritual. 
A abordagem dualista do problema mente-corpo sustenta que a natureza da mente e da inteligência consciente, ou da alma ou espírito, está em algo não físico, e que não pode ser compreendido ou reduzido em termos dos conceitos das ciências físicas. Esta qualidade não física é independente, mas se conecta aos corpos físicos. O filósofo René Descartes (1596-1650) formatou o chamado dualismo da sustância (CHURCHLAND, 2004: 27). A teoria cartesiana instituiu uma importância não somente para a substância pensante, por meio do célebre "penso, logo existo", mas para a substância material, que ocupa extensão no espaço. Porém a substância mental restou ainda ausente de atributos físicos. Um problema já se impunha a Descartes: se a substância mente é diferente da substância corpo, como se daria a influência causal da substância incorpórea sobre a matéria? O filosofo acomodou o problema sugerindo que eram os "espíritos animais", uma substância material muito sutil, que transmitia a influência da mente sobre o corpo. A máquina do corpo seria movida pela alteração dos movimentos dos espíritos, cabendo a estes abrir espaços no cérebro. $\mathrm{O}$ contato direto entre as duas substâncias se daria por meio da glândula pineal, a única parte do cérebro capaz de unificar as imagens dos sentidos, por não possuir a conformação dupla comum à estrutura cerebral e aos órgãos do sentido.

A separação entre mente e corpo por meio da categorização de substâncias tornou-se tênue, mas a teoria do "fantasma na máquina" corpo é visto como um mecanismo comandado por uma substância misteriosa de constituição totalmente diferente, ainda nos assombra. Na possibilidade de se pensar o ator como um sujeito não cartesiano, novas relações devem se estabelecer entre corpo e mente, se constituindo como tópicos essenciais para discussão do problema da ação. $\mathrm{O}$ ato pensante e o ato consciente passam a ser entendidos como implementados no corpo em ação no mundo, não mais como atributo de uma razão descolada ou anterior à experiência. A mente, pela lente das teorias das ciências cognitivas, é encarnada, corporificada, e não responde exclusivamente a uma condição a priori.

Os estudos sobre a mente e suas conexões com o corpo tem sido um dos campos epistemológicos mais férteis na atualidade. Filósofos-cientistas que pesquisam estas questões, como Damásio (1996, 2000, 2004) e Churchland (2004) não duvidam da fisiologia dos estados mentais e do correlacionamento dos processos do corpo e da mente. Acredito que estes novos entendimentos podem auxiliar o ator a trabalhar "sobre si mesmo" e sobre suas ações, incidindo numa possível transformação de sua prática cênica. A constituição das ações é um processo de conhecimento, e o problema epistemológico do trabalho do ator consiste em averiguar os procedimentos que cercam o próprio ato de conhecer. Ao perceber a rede complexa de conexões que consiste em seus atos, o ator poderá compreender mais amplamente seus processos de conhecimento de si mesmo e do mundo.

${ }^{13}$ Gilbert Ryle, em $O$ conceito de mente (1949), elabora críticas ao dualismo fazendo alusão à metáfora do fantasma na máquina.

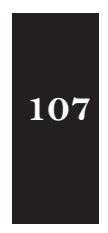


O trabalho do ator "sobre si mesmo" implica num certo tipo de conhecimento, que não é só a construção de um modelo teórico sobre as relações corpo e mente, mas envolve a complexidade da ação humana e a imprevisibilidade das relações espaços-temporais momentâneas. A arte do ator tende a permanecer ainda no início do século XXI como a arte do vivo, da experiência da presença, requisitando constantemente a revisão ontológica, epistemológica e pedagógica do corpomente em ação.

\section{Referências}

ABBagnanO, Nicola. Dicionário de Filosofia. São Paulo: Martins Fontes, 2000.

BARBA, Eugênio. La fiction de la dualité. In: Théatre qui Danse. Bouffonneries, 1989, n. 22/23.

BOGDAM, Lew. Stanislavski, le Roman Théâtraldu siécle. Saussan: L'EntreTemps Éditions, 1999.

CHURCHLAND, Paul. Matéria e consciência. Uma introdução contemporânea à filosofia da mente. São Paulo: Editora UNESP, 2004.

DAMÁSIO, António. O mistério da consciência. São Paulo: Companhia das Letras, 2000.

O erro de Descartes. São Paulo: Companhia das Letras, 1996.

Em busca de Espinosa: prazer e dor na ciência dos sentimentos. São Paulo: Companhia das Letras, 2004.

DENNETT, Daniel. Tipos de Mente. Rumo a uma compreensão da consciência. Rio de Janeiro: Rocco, 1997.

GROTOWSKI, Jerzy. Em busca de um teatro pobre. Rio de Janeiro: Civilização Brasileira, 1992.

Respuesta a Stanislavski. In: JIMENEZ, Sérgio. El evangelio de Stanislavski segun sus apostoles, los apócrifos, la reforma, los falsos profetas y Judas Iscariote. México: Editorial Gaceta, 1990. p.487-504 (Coleción Escenologia).

HORMIGON, Juan Antônio. Meyerhold: textos teóricos. Madrid: Imprensa de la Comunidad de Madrid, 1992. (Série teoria y prática del teatro).

ISAACSSON, Marta. O passado, origem da autenticidade do presente, nas pesquisas de Stanislávski e Grotowski. Urdimento. Teatro e memória, Revista de Estudos Pós-graduados em Artes Cênicas. Programa de Pós-graduação em Teatro da UDESC, Florianópolis, n. 6, p.9-19, dez. 2004. Universidade do Estado de Santa Catarina.

JIMENEZ, Sergio. El evangelio de Stanislavski segun sus apostoles, los apócrifos, la reforma, los falsos profetas y Judas Iscariote. México: Editorial Gaceta, 1990. 
(Coleción Escenologia).

PIDOUX, Jean-Yves. Acteurs et personnages: L'interpretation dans les esthétiques théâtrales du XXé siécle. Suisse: L’Aire Théâtrale, 1986.

RIBOT, Théodule. La Psychologie des Sentiments. 16. ed. Paris: Alcan-Press Universitaires de Paris, 1939.

RICHARDS, Thomas. At work with Grotowski on physical actions. London: New York: Routledge, 2001.

SERRANO, Raúl. Tesis sobre Stanislavski en la educación del actor. Cidade do México: Escenologia, A.C, 1996

Nuevas Tesis de Stanislavski: Fundamentos para una teoría pedagógica. Buenos Aires: Atuel, 2004.

STANISLAVSKI, Constantin. El trabajo del actor sobre si mesmo. El trabajo sobre si mesmo en el proceso creador de las vivencias. Tradução por Salomón Merener da edição russa da Editora Estatal Arte, do Instituto Estatal de Investigações Científicas de Teatro e Música "Maximo Gorki”, de Moscou. Buenos Aires: Domingo Cortizo - Editorial Quetzal S.A., 1986.

El trabajo del actor sobre su papel. Tradução por Salomón Merener da edição russa da Editora Estatal Arte, do Instituto Estatal de Investigações Científicas de Teatro e Música "Maximo Gorki”, de Moscou. Buenos Aires: Domingo Cortizo - Editorial Quetzal S.A., 1988.

El trabajo del actor sobre si mesmo. El trabajo sobre si mesmo en el proceso creador de la encarnacion. Tradução por Salomón Merener da edição russa da Editora Estatal Arte, do Instituto Estatal de Investigações Científicas de Teatro e Música "Maximo Gorki”, de Moscou.. Buenos Aires: Domingo Cortizo Editorial Quetzal S.A., 1986.

A criação de um papel. Rio de Janeiro: Civilização Brasileira, 1995.

Minha vida na arte. Rio de Janeiro: Civilização Brasileira, 1989.

Ma vie dans l'art. Tradução do russo por Denise Yoccoz. Lausanne: L'Age D'Homme, 1980.

Las acciones fisicas como metodologia. In: JIMENEZ, Sergio. El evangelio de Stanislavski segun sus apostoles, los apócrifos, la reforma, los falsos profetas y Judas Iscariote. México: Editorial Gaceta, 1990. (Coleción Escenologia). 